\title{
Teaching Methods of Computer Education under the Background of Big Data
}

\author{
Xiang $\operatorname{Nan}^{1}$ \\ ${ }^{1}$ The Kyoto College of Graduate Studies for Informatics
}

\begin{abstract}
With the advancement of society and the increase of computer, network and digital media technology, big data technology has become an indispensable part of modern service industry. Big data technology has been developed in all aspects of the education industry, and the value of products and services created has gradually increased. Big data plays an important role in technology in computer education and other aspects. This article mainly introduces the teaching method research of computer education under the background of big data. This article uses the research of the teaching method of computer education under the background of big data, starting from the two aspects of computer education and basic courses, rationally analyzing the feasibility of the teaching method of computer education. From the labor market in our country, the demand for computer talents is concentrated on application-oriented talents, but the purpose of computer education in many schools mostly stays in traditional research-based teaching, resulting in a decline in the quality of education, and it is difficult to meet the market's demand for computer application-oriented talents. It is the main body that determines the course content and teaching mode. The experimental results of this paper show that the research on the teaching methods of computer education under the background of big data has increased the efficiency of computer education by $18 \%$. The limitations of the research on the teaching methods of computer education under the background of big data are analyzed, and the methods and ways of computer ability training are analyzed. Discuss and summarize, so as to enrich the academic research results.
\end{abstract}

\section{Introduction}

At present, our country's computer education has been vigorously developed and made great progress, and the application scope of big data technology has increased nearly four times. In the next ten years, the global data storage capacity will increase tenfold, and this trend will continue for a long time [1-2]. The value of big data is obvious to everyone [3-4]. Big data can not only provide commercial value, but also enable people to get rid of old values and development concepts, enabling them to understand the development of world technology and the emergence of complex technologies with new perspectives and thinking [5-6]. At the same time, big data has also changed people's attitudes and perceptions in work, study and life.

Computer education started early, has formed a complete theoretical and theoretical department and summed up a wealth of practical experience. Esmer E pointed out that there are two different curriculum systems in the article "How to Position Computer Teaching in Vocational Schools": one is to set up courses according to disciplines, first systematically learn basic theoretical knowledge, and emphasize the systematic and completeness of theory [7]. Wang $\mathrm{X}$ believes that we should connect with reality and carry out applications; the other is an education model with application as the goal [8]. Set up courses according to application needs, learn from application in teaching, learn what is needed, and use computers as tools and means to deal with problems [910]. However, there are errors in their experimental process, resulting in insufficient accuracy.

The innovation of this article is to put forward the teaching method research of computer education under the background of big data. Study the teaching situation of computer education under the background of big data, and analyze the effective countermeasures of computer course teaching. This part proposes corresponding countermeasures to the problems existing in the teaching classroom, namely, formulating scientific talent training goals, innovating training models, and strengthening the construction of teaching staff. The aim is to find a new path for the development of teaching methods suitable for computer education in the current big data environment through this research. 


\section{Computer Education in the Big Data Environment}

\subsection{Computer Education Environment}

With the continuous development and wide application of computer technology, people have developed many computer examination systems for different examinations to strengthen the assessment and management of courses. The computer examination system is a software platform for course assessment realized by computer technology in a stand-alone or network environment. In the teaching of computer courses, some courses only need to carry out a variety of theoretical learning, and some courses need to be at the same time as theoretical learning. Strengthen computer practice, and some courses mainly use computers to learn software operation skills. In order to distinguish these courses, we call the courses that need to be practiced on the computer as computer practice courses. Now, the assessment of computer practice courses not only adopts the form of paper medium test papers composed of objective and subjective questions, but also has courses.

With the participation of computers, the purpose of computer education is no longer just to impart knowledge, but to integrate the practicality and knowledge of teaching, so that students can participate in the whole of computer education through personalized and autonomous learning, process, actively cultivate the ability of self-study and self-evaluation. Big data technology can simulate a real language environment, firmly grasp the attention of students, and greatly broaden the content and themes of reading, speaking, and writing in English learning, allowing students to be trained in multiple skills. Multimedia teaching is a model that focuses more on "learning" rather than "teaching". Students turn from passive receivers of knowledge to active builders of knowledge and the main body of learning activities. In multimedia teaching, teachers' main tasks are curriculum design and teaching task planning, and the guide and facilitator of students' knowledge acquisition: the student's task is to explore, discover and solve problems, cultivate autonomous learning consciousness and creative thinking. Students have more room to play. An autoregressive $\mathrm{AR}(\mathrm{P})$ model for computer education refers to a time series and has the following form.

$$
X_{\mathrm{t}}=\sum_{\mathrm{i}=1}^{\mathrm{p}} \mathrm{a}_{i} x_{t-i}+\varepsilon_{t}
$$

Among them is the learning influence factor, which can be expressed as:

$$
\text { si } \operatorname{gmoid}(x)=\max (\operatorname{LdotN}, 0.0)
$$

The autoregressive moving average $\operatorname{ARMA}(p, q)$ model of computer teaching is a combination of the following forms;

$$
\alpha(L) X_{\mathrm{t}}=\theta(L) \varepsilon_{\mathrm{t}}
$$

\subsection{Computer Education Research Method}

University computer education pays attention to how to improve students' comprehensive computer ability. This is also the requirement of society and the job market for talent training in universities. In the reform of computer education, teachers should emancipate their minds and actively learn advanced educational theories and teaching methods; students should work hard to learn independently, improve the ability of comprehensive computer use, and enhance the level of comprehensive knowledge. Teachers should cultivate college students' comprehensive computer application ability, and cultivate more IT talents according to the needs of society and the job market. For a practical course such as computer, the application, practicality, innovation and knowledge update of the teaching content and knowledge structure cannot keep up with the development and changes of new technologies, and it lacks the training of students' practical and innovative abilities. It can only enable students to complete the corresponding level of academic education, and lack the sustainable development ability to adapt to the renewal of employment positions, resulting in the inability to train qualified graduates that truly meet the needs. It can be seen from the above data that, on the one hand, it faces a shortage of mid-level computer application talents, while on the other hand, higher vocational schools cannot provide qualified graduates.

An important part of the computer science teacher's education and method work is the quality control of the knowledge system acquired by the students, which involves experimental teaching activities. This kind of experimental teaching activities includes teaching experiments, and the experimental results are processed and analyzed by mathematical methods. Teaching measurement allows to prove the effectiveness of the implemented teaching methods. Teaching measurement is carried out in teaching research and aims to improve the content, methods, forms and means of using teaching games to teach computer science to young students. The teaching experiment itself includes the stages of determination, exploration, formation and control. Using mathematics and statistical methods, the results of teaching measurement can be effectively analyzed to determine the quality of the knowledge acquired by young students in computer science. How to improve the ability of using computers, how to learn autonomously and individualized learning ability of college students.

\section{Computer Basic Courses under Big Data}

\subsection{Current Situation of Computer Basic Courses}

It has only been about twenty years since colleges and universities across the country opened basic computer courses. With the development of the times, disciplines and fields have penetrated each other, and computer knowledge and technology have been widely used in various fields. The emergence and development of computer education, discuss the guiding significance of 
learning theory, the theory of human all-round development and the theory of lifelong education to innovative education research. Carry out surveys on the learning interests, learning initiative, innovative consciousness, and innovative capabilities of noncomputer students in colleges and universities, understand the current teaching status of computer basic courses and the implementation of innovative education in colleges and universities, find out existing problems, and analyze in depth, provide a realistic basis for formulating a solution strategy.

Study the learning psychology and cognitive structure of students, explore effective teaching models that are conducive to cultivating students' innovative consciousness, innovative spirit and innovative ability, and use these models comprehensively to construct an innovative teaching model for basic computer courses. Apply the innovative teaching mode of basic computer courses to actual teaching, conduct teaching experiments, analyze the teaching effect, and verify the feasibility. Reflecting on the limitations of research, in order to stand out in the fierce international competition, many foreign developed countries are stepping up adjustments to the strategy of science and technology, education and economic development, and the reform and development of education is crucial, and innovative education has been highly valued and the study.

\subsection{Computer Teaching Methods}

Historical documentation method. From the perspective of historical development, combining the research experience and conclusions of predecessors, we can find out the theories of this research and sort out the clues and context of this research. In addition to consulting library materials, read journals, papers and works, have a deep understanding of related basic concepts and theories, and grasp the current situation and causes of computer education to lay the foundation for this research; questionnaire survey method. In order to obtain more accurate data, this study conducted a questionnaire survey with students majoring in pre-school education at two adult higher education institutions in the province, and used the "Questionnaire on the Current Situation of Computer Education" compiled by Chen Xuewen to investigate the current status of the school's computer education level. The questionnaire survey analyzes the problems existing in the computer teaching of the major students at this stage, and then proposes corresponding countermeasures for the promotion of computer education.
Interview method. Through structured interviews with teachers and students of computer education majors, we can understand relevant information such as the computer education professional ability training program and their opinions and suggestions on the reform and innovation of computer education ability training. The research review on teaching ability came into being with the emergence of daily learning. It is considered to be the product of the mutual penetration of humanistic literacy and computer education for a certain period of time. Computer is not limited to a certain subject or field but is open. . The specific results are shown in Table 1.

Table1. political education evaluation index and influence factor

\begin{tabular}{|c|c|c|}
\hline Brand influence & Subject influence & group influence \\
\hline market share & Popularity & grassroots \\
\hline Social reputation & People-oriented & ecological design \\
\hline Develop innovation & $\begin{array}{c}\text { innovation in } \\
\text { teaching and } \\
\text { innovation in } \\
\text { scientific research }\end{array}$ & $\begin{array}{c}\text { innovation in } \\
\text { practice and } \\
\text { education, }\end{array}$ \\
\hline
\end{tabular}

\section{Applied Computer Teaching Analysis}

\subsection{Language Development Process in Computer Education}

With the development of the times, human life style has undergone earth-shaking changes. The computer used in the high-tech field has entered the daily life of ordinary people and has become one of the key tools for modern people to study, work and relax. Whether the computer is used for scientific research or as a necessary tool in daily life, computer users must master some computer knowledge and operating skills, the problem of computer education stems from this. The development of computer education has almost gone through two stages, focus on language teaching before, and today, people worry about programming methods. At that time, there was a trend in the world that "computer science is equal to program". The FORTRAN language was first researched and developed by scientists. It appeared in 1963. BASC language, and then LOGO language in 1967. These languages are constantly evolving, laying the foundation for the popularization of computers. The specific results are shown in Figure 1. The applicability of BASC language is lower than that of LOGO. 


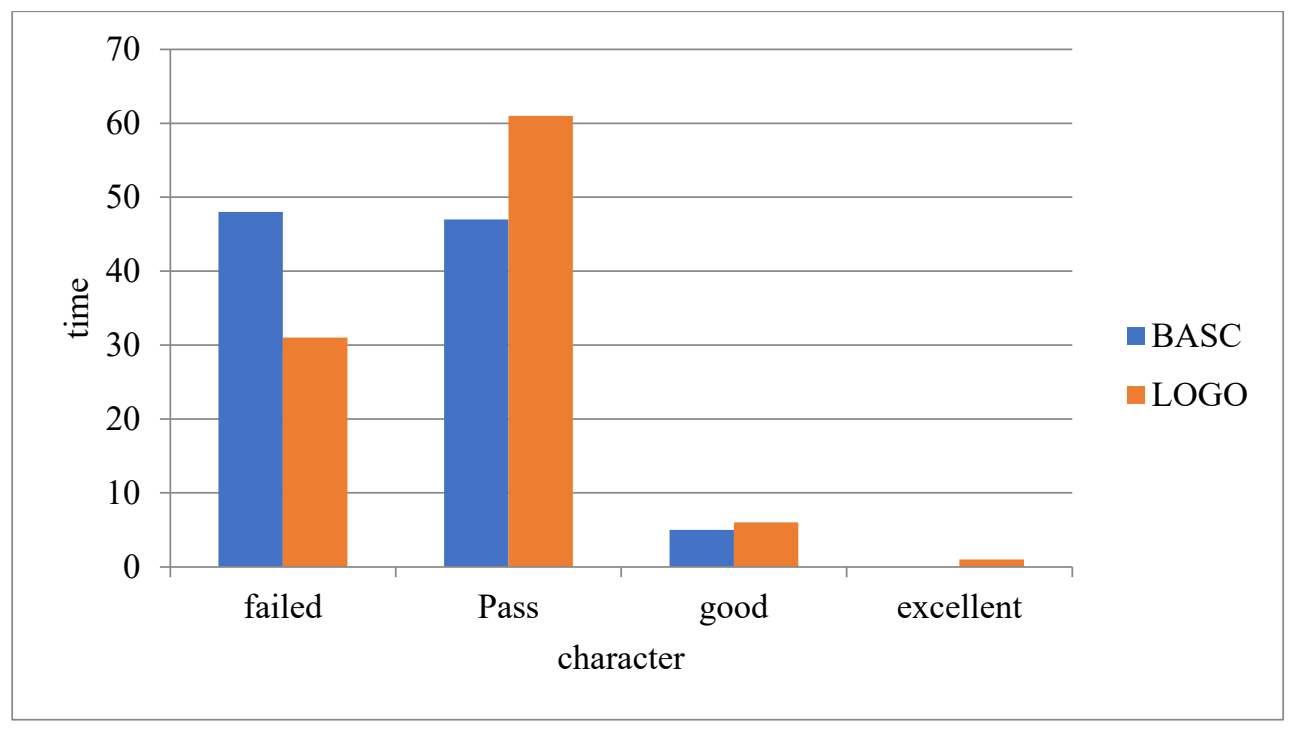

Figure 1. Interviewed students' participation in artistic ability training

\subsection{Current Situation of Computer Application}

After our country's first electronic computer "103 machine" was successfully developed in 1958, computer majors were opened in some key universities, mainly to train scientific researchers and engineering technicians. However, due to the influence of the special era, the development of computer education in our country was quite slow. Until the end of the 1970s, computer education was very backward, not to mention the popularization of computer education. It can be seen that during this period, computer courses were mostly programming languages, and the computers at that time were huge and expensive. There were not many people who could use or even see computers. Therefore, only a few people who master computer knowledge and skills, especially Scientists and technicians engaged in high-tech research. The specific results are shown in Table 2.

Table2. model browser

\begin{tabular}{|c|c|c|c|c|}
\hline & \multicolumn{2}{|c|}{ Control group } & \multicolumn{2}{c|}{ test group } \\
\hline project & $\mathrm{M}$ & $\mathrm{SD}$ & $\mathrm{M}$ & $\mathrm{SD}$ \\
\hline Speech flow technology & 3.41 & 842 & 3.77 & 3.34 \\
\hline
\end{tabular}

\begin{tabular}{|c|c|c|c|c|}
\hline Tone technique & 3.28 & 826 & 3.65 & 3.14 \\
\hline Sentence refinement & 3.04 & 838 & 3.39 & 2.96 \\
\hline
\end{tabular}

In the information society, mastering the basic knowledge and skills of computer applications has become one of the criteria for measuring whether a person is capable of a specific job, and also one of the criteria for measuring the qualifications of college graduates. In such a social environment, computers are no longer just run by some professionals, but have become a learning tool. The demand for mastering basic computer knowledge and basic skills is increasing. The teaching of basic computer knowledge and basic skills has been valued since the 1980s. The rapid development of computer software and hardware technology has strongly promoted the development of other disciplines. The widespread use of computers has penetrated into all areas of society. At the beginning of 1984, Deng Xiaoping pointed out that "the popularization of computer should start from the baby", which greatly promoted the development of computer education in our country. With the development of society, computer education has been placed in a prominent position. The specific results are shown in Figure 2. The computer skills of the students in the computer class are higher than those of the ordinary class, and the computer skills of the students in the experimental class are significantly improved. 


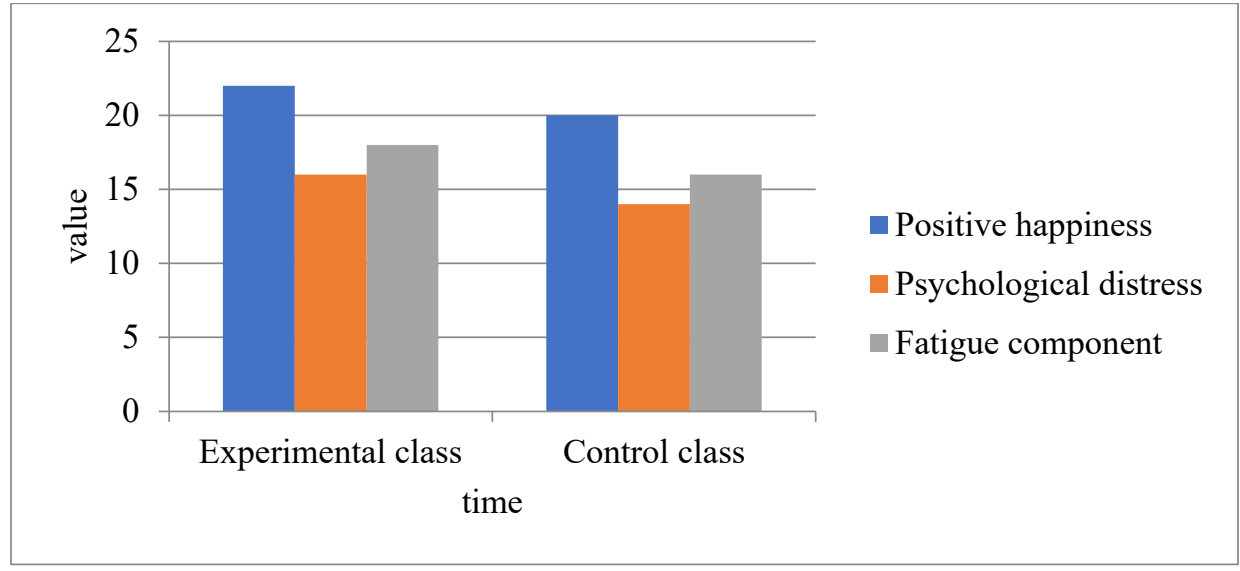

Figure 2. Questionnaire

\section{Conclusions}

Although this paper studies the teaching methods of computer education under the background of big data, there are still many shortcomings. Computer education requires not only extensive theoretical knowledge, but also a solid theoretical foundation and competence. Based on the background of big data, there are still many indepth content in the research of computer education teaching methods. There are still many steps in the analysis of computer teaching methods that have not been covered because of space and personal ability. In addition, the practical application effects of related experiments in computer basic classrooms can only be compared with traditional models from the level of theory and simulation.

\section{References}

1. Li Y, Tian S, Huang Y, et al. Driverless artificial intelligence framework for the identification of malignant pleural effusion[J]. Translational Oncology, 2021, 14(1):100896.

2. Hassabis D, Kumaran D, Summerfield C, et al. Neuroscience-Inspired Artificial Intelligence[J]. Neuron, 2017, 95(2):245-258.

3. $\mathrm{Lu} \mathrm{H}, \mathrm{Li} \mathrm{Y}$, Chen M , et al. Brain Intelligence: Go Beyond Artificial Intelligence[J]. Mobile Networks and Applications, 2017, 23(7553):368-375.

4. $\mathrm{Ng} \mathrm{T} \mathrm{K} \mathrm{.} \mathrm{New} \mathrm{Interpretation} \mathrm{of} \mathrm{Extracurricular}$ Activities via Social Networking Sites: A Case Study of Artificial Intelligence Learning at a Secondary School in Hong Kong $[\mathrm{J}]$. Journal of Education and Training Studies, 2021, 9(1):49-60.

5. Camerer $\mathrm{C} \mathrm{F}$. Artificial Intelligence and Behavioral Economics[J]. NBER Chapters, 2018, 24(18):867-71.

6. Hassabis, Demis. Artificial Intelligence: Chess match of the century[J]. Nature, 2017, 544(7651):413-414.

7. Jia-zhan, Su, Xi-lun, et al. Full-scale bending test and parametric study on a 30-m span prestressed ultrahigh performance concrete box girder:[J]. Advances in Structural Engineering, 2019, 23(7):1276-1289.
8. Esmer E, Gülin Güven, Aydn O, et al. Perceptions of education faculty students on teaching methods and materials $[\mathrm{J}]$. Educational Research \& Reviews, 2016,11(12):1093-1109.

9. Wang X, Zhu L, Liu X . Project-oriented Teaching Method for Computer Simulation of Automatic[J]. International Journal for Innovation Education and Research,2019,7(4):118-122.

10. Needhi, Kotoky, Anjan, et al. Hybrid testing for evaluation of seismic performance of highway bridge with pier made of HyFRC - ScienceDirect[J]. Structures, 2019, 20:848-865.

11. Yuanyao M, Ditao N . Effect of Vehicle Load on the Fatigue Performance of Corroded Highway Bridge[J]. Science of Advanced Materials, 2018, 10(6):845-852. 